\title{
Role of the accident and emergency department in the non-heart-beating donor programme in Leicester
}

\author{
T B Hassan, M Joshi, D N Quinton, R Elwell, J Baines, P R F Bell
}

Leicester Royal

Infirmary, Leicester,

United Kingdom:

Department of

Accident and

Emergency Medicine

T B Hassan

M Joshi

D N Quinton

Department of

Surgery

P R F Bell

Department of

Surgery, Leicester

General Hospital,

Leicester

R Elwell

J Baines

Correspondence to: Dr T B Hassan, senior registrar in accident and emergency medicine, Leicester Royal Infirmary, Infirmary Square, Leicester LE1 5WW.

Accepted for publication 13 March 1996

\begin{abstract}
Objective-To describe the development of a non-heart-beating donor (NHBD) programme in an accident and emergency (A\&E) department over a three year period.

Background and methods - The A\&E department at the Leicester Royal Infirmary at present deals with approximately 200 prehospital cardiopulmonary arrests per year. A programme of kidney retrieval from non-heart-beating donors was started in April 1992. Strict criteria for admission to the programme, appropriate consent procedures, facilities, lines of communication, and feedback were developed to enhance its success.

Results - Of 66 patients referred to the NHBD programme over a three year period from 1 April 1992, 51 sets of relatives were available to be asked for possible organ donation, and 34 sets (66\%) gave their consent. Twenty five patients had successful in situ perfusion of the kidneys. Forty seven organs were retrieved and 34 went on to be transplanted. To date, 27 kidneys are still working. As a result, $23.8 \%$ of kidneys transplanted in Leicester over this time period have been from the NHBD programme.

Conclusions-The NHBD programme in Leicester has proved very successful, requiring organisation of resources and personnel both from the transplant service and the A\&E department. The programme has provided such a significant boost to the renal transplant rate in Leicester that other hospitals with large A\&E departments should consider setting up similar programmes.

(F Accid Emerg Med 1996;13:321-324)
\end{abstract}

Key terms: non-heart-beating donor; renal transplantation; resources; personnel

The continuing shortfall in the number of kidneys available for transplantation in the United Kingdom ${ }^{1}$ has led to the successful development of alternative sources from non-heartbeating donors (NHBD). ${ }^{2}$ Varty et al ${ }^{2}$ described the initial experience in Leicester, showing that 19 of 27 referrals were from patients who had undergone unsuccessful resuscitation in the accident and emergency (A\&E) department following cardiopulmonary arrest in the community. The procedure they described allows emergency in situ perfusion by cannulation of the femoral vessels and isolation of the kidneys. Hence, this limits the warm ischaemia time before transplantation. Similar success has been reported from NHBD programmes elsewhere in Europe. ${ }^{34}$

The high proportion of such referrals from the $A \& E$ department reflected its important role in the success of the programme.

After three years, most referrals continue to be from the $A \& E$ department. No previous reports have discussed this essential role in such programmes. We describe the development of this retrieval system within our department and its logistic impact, both on the department and the transplant service in Leicester.

\section{Methods}

ORGANISATION

The A\&E department at the Leicester Royal Infirmary, serving a population of 900000 , sees approximately 100000 new patients per year. Of these, some 200 have suffered a prehospital cardiopulmonary arrest. Most prehospital cardiopulmonary arrest are known to carry a poor prognosis, often as a result of limited access to immediate advanced life support (ALS) measures, particularly defibrillation. ${ }^{56}$ They are therefore potentially a useful source for a NHBD programme. In 1992, the programme in Leicester was launched by the University Department of Surgery in conjunction with the A\&E department. After discussions with the coroner, the local ethics committee, and senior medical and nursing staff within the hospital, a proposal for instituting a hospital-wide non-heart-beating donor programme was developed. Proposals were also discussed with various local groups, including the press, to gauge public opinion.

Within the A\&E department, proposals for instituting the programme were presented to the staff and active multidisciplinary medical and nursing discussion took place. This was supplemented by further meetings during the first year in order to identify and correct teething problems and further educate staff on the success of the programme.

CRITERIA FOR ADMISSION TO THE PROGRAMME Patients under the age of 65 years who had undergone unsuccessful resuscitation following prehospital or intradepartmental cardiopulmonary arrest were eligible to be included in the programme. Exclusion factors included an 
Table 1 Details of the donors

Total number of cardiopulmonary arrests 1992-1995

Total number of referrals to the transplant team

Male/female ratio

Mean age (whole group)

Mean age (successful retrieval group)

Mean resuscitation time in successful donors

Mean resuscitation time in unsuccessful donors
$57: 11$

43.9 years $(19-64)$

44.8 years $(22-63)$

$65 \mathrm{~min}(30-92)$

$58 \mathrm{~min}(26-96)$

unwitnessed cardiac arrest where no basic life support (BLS) measures had been instituted for a period of 30 minutes or more, known malignancy, known renal disease or diabetes mellitus, and infection as a likely cause for the cardiopulmonary arrest. After the second year, the criteria for age was changed to exclude those over the age of 60 years since several retrievals in the 60-65 year age group had failed as a result of poor perfusion.

\section{CONSENT AND PROCEDURE}

Once a resuscitation attempt had been officially terminated by the $A \& E$ staff, the transplant team were contacted. Relatives of the deceased were informed of the death of their loved ones immediately if they were available. The difficult issue of organ transplantation was broached only by a senior member of the transplant team or A\&E staff. In those circumstances where relatives were not immediately available, the procedure to perfuse the kidneys was instituted temporarily and subsequently withdrawn if permission was refused. Perfusion in such cases was continued up to a maximum of 90 minutes. This particular aspect of the programme met with the approval of both the coroner and the ethics committee.

The procedure of in situ perfusion adopted by Booster et al ${ }^{7}$ was used to achieve renal cooling. This employed a triple lumen kidney transplant catheter with a rapid 8 litre infusion of chilled $\left(4^{\circ} \mathrm{C}\right)$ kidney perfusion solution and subsequent slower infusion.

\section{PERSONNEL}

The A\&E department cardiac resuscitation team consists of two to three doctors, three trained nurses, and an operating department assistant (ODA). Once resuscitation has been terminated and the patient declared dead, they are moved to another area of the department (the $A \& E$ operating theatre), where ventilation and cardiac massage is continued to ensure some renal perfusion while the renal catheter is being positioned by the transplant team. During the first year, this occupied the services of at least two nurses and the ODA. Subsequently, a mechanical device for cardiac massage and ventilation was used (Thumper CPR System-Michigan Instruments), releasing these personnel. A senior member of the A\&E staff or transplant team is also constantly involved with the bereaved relatives during this time.

COMMUNICATIONS AND FACILITIES

Rapid access to the transplant team is essential in order to achieve success in such programmes. During weekday working hours, this

is more easily achieved as the transplant registrar (responsible for placement of the catheter) and the transplant coordinator are available on site at the hospital. After hours and at weekends, a delay of 15-20 minutes ensues while the relevant personnel arrive from home.

Within the A\&E department, facilities for storing large quantities of the cold perfusate and appropriate surgical equipment are required, as well as an area where the procedure for placement of the catheter can take place.

\section{FEEDBACK}

Following the successful launch of the programme, several informal meetings between the transplant team, the nursing team, and the medical teams have continued in order to identify areas for improvement within the programme. Feedback on successful donations and the ultimate success of the transplanted kidneys is provided by the transplant coordinator.

\section{Results}

During the three year period, 1 April 1992 to 31 March 1995,582 prehospital or intradepartmental cardiopulmonary arrests were identified by either the dedicated cardiac arrest database or the departmental patient registration computer system. The NHBD transplant programme began at the same time and, during this same period, 66 referrals to the transplant service were identified. Patients referred were predominantly male (approximate male to female ratio $5: 1$ ), with a mean age of 43.9 years. This was very similar to the mean age of the patients who subsequently had a successful retrieval performed. All referrals made to the transplant service were in patients who had initially been identified as having suffered a witnessed cardiopulmonary arrest, and most cases had had prolonged resuscitatory efforts by the Leicestershire Ambulance and Paramedic Service. On arrival in the A\&E department, all patients underwent a further shorter period of resuscitation along standard European Resuscitation Council guidelines ${ }^{8}$ before efforts were terminated. The mean resuscitation time in the two groups from onset of collapse to termination of the resuscitation attempt was 58 and 65 minutes. These data are summarised in table 1 .

Four of the 66 patients suffered a cardiopulmonary arrest in the resuscitation room and had significantly reduced resuscitation times (mean 28 minutes, range 26 to 35 minutes). Unfortunately, none of these patients went on to have a successful retrieval. In two, relatives refused permission; in another, relatives were not contactable; in one retrieval was unsuccessful due to technical difficulties.

Of the 66 patients referred to the transplant service, 25 had successful in situ perfusion of their kidneys performed followed by an organ retrieval procedure. In these patients, 47 kidneys were retrieved and 34 went on to be successfully transplanted. To date 27 kidneys are still working. Of the 51 sets of relatives who were asked, $34(66 \%)$ gave their consent and 17 refused. 
Table 2 Outcome of referrals to the transplant service for the NHBD programme

\begin{tabular}{ll}
\hline Successful retrievals & 25 \\
Failed retrievals & 41 \\
Technical errors & 7 \\
Relatives refused & 17 \\
Relatives unavailable & 8 \\
Donor unsuitable & 4 \\
Prolonged resuscitation period & 3 \\
Transplant staff unavailable & 1 \\
Coroner unavailable & 1 \\
\hline
\end{tabular}

Eight sets of relatives were uncontactable within the 90 minute limit time for perfusion. In seven patients, a variety of technical errors mainly related to catheter placement resulted in unsuccessful retrieval and in two cases the transplant team or coroner were unavailable. In seven others the procedure was subsequently aborted either because further inquiry suggested prolonged cardiopulmonary arrest with no BLS being carried out, or because of the identification of exclusion factors. Data on failed retrievals are summarised in table 2 .

The figure shows the times of referral of patients to the transplant service over a 24 hour period. Almost a half of referrals were made between 9.00 am and $5.00 \mathrm{pm}$. It is notable, however, that seven of the 25 successful retrievals occurred outside these hours. The aetiology of the cardiopulmonary arrests for 46 patients who were initially admitted to the programme is shown in table 3. The main causative factor was coronary artery disease.

\section{Discussion}

The NHBD programme, the first of its kind in the United Kingdom, has proved to be successful in significantly increasing the transplant rate of kidneys in Leicester. During the three year period, the programme has provided $23.8 \%$ of the total number of kidneys transplanted in Leicester. Interestingly, although ours has been a hospital-wide programme, there have been many fewer referrals from the rest of the hospital. This relates to a variety of factors. Essential among these is a greater enthusiasm for the programme from within the A\&E department, allied to a significant commitment, good communication, and flexibility among the staff. The NHBD programme has also fitted in well with the existing bone, cornea, and heart valve retrieval programmes already present within the department.

The A\&E department is one of the busiest in the country. As a result, it is responsible for dealing with a large number of cardiopulmonary arrests, a significant proportion of which are unfortunately unsuccessful. Success rates for treating prehospital cardiac arrests in Leicestershire are, however, equivalent to other reported data in the United Kingdom. ${ }^{9}$ In the last three to four years, the number of prehospital cardiopulmonary arrests being brought to the $A \& E$ department has steadily increased and this is undoubtedly related to greater awareness and usage of basic and advanced life support skills by paramedic staff in the community. Similar increases in the number of cardiopulmonary arrests being treated in the $A \& E$ department since the inception of pre-

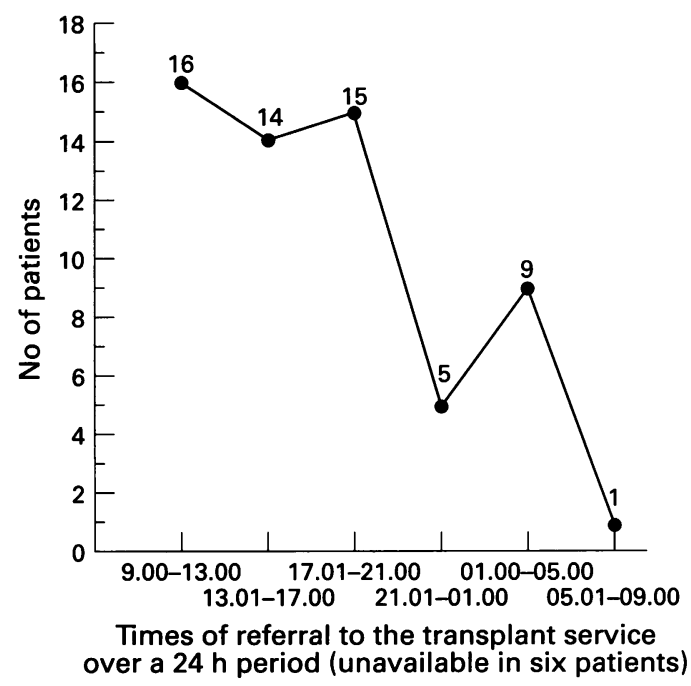

Times of referral for individual patients to the programme.

Table 3 Aetiology of cardiopulmonary arrest in patients submitted to the NHBD programme

Coronary artery disease $\quad 31$

Valvar disease

Dissection of the thoracic aorta

Idiopathic cardiomyopathy

Pulmonary hypertension secondary to an atrio-septal defect

Myocarditis

Asthma

Meningitis

Drowning

Alcoholic poisoning

Small bowel infarction secondary to volvulus

Status epilepticus

Necropsy not performed

hospital programmes have been reported elsewhere. ${ }^{10}$ It is also notable that almost all referrals to the NHBD programme were related to a medical cause for collapse, chief among these being coronary artery disease. There was, however, one trauma case, a 19 year old who suffered a fatal cervical spine injury while playing football. Fatal trauma cases may, in the future, be an additional source for the programme.

Undoubtedly, one of the main difficulties in having an NHBD programme based mainly in the $A \& E$ department is the initial unavailability of relatives in the acute resuscitation situation. The advantage of immediate in situ perfusion is that the procedure allows the warm ischaemia time to be prolonged by one to two hours until relatives can be located. However, because of the acuteness of the event, the relatives are often poorly prepared to accept bad news. As a result, the task of discussing possible organ donation is made all the more difficult. The experience of the transplant team and senior staff in A\&E in Leicester is that this does not seem to increase the likelihood of refusal. In our series, 17 out of 51 sets of relatives (33\%) who were available to be asked refused permission for donation of organs. Gore et al ${ }^{11}$ quoted a figure of $30 \%$ of relatives refusing permission for organ donation in patients who were brainstem dead on an intensive care unit. Our success rate for consent therefore compares favourably with that of Gore and his colleagues, who often had more time to build up a 
rapport with relatives. The importance of having senior personnel experienced and trained in broaching such difficult issues cannot be overstated. This has been found to be an important factor in poor rates of organ donation.

In several patients retrieval failed because of a variety of mechanical errors. These were often related to the difficulty in passing the catheter through atherosclerotic large vessels. Inadequate positioning of the catheter and a number of other anecdotal causes have steadily been eliminated as reasons for the procedure failing. Similar difficulties have been encountered in other programmes. Booster et $\mathrm{al}^{7}$ identified 61 potential NHBD patients over a 10 year period. Relatives of the patients were not present in eight cases or refused permission for donation of organs in four. Successful retrieval occurred in 49 patients, resulting in 98 kidneys, 28 of which were subsequently discarded for a variety of reasons. However, their procurement rate for kidney transplants increased by $20 \%$ as a result. They, too, are strong advocates of an NHBD programme.

Although call out for the transplant team occurs on a relatively infrequent basis, it is important to continue communication links in order to foster good relationships and maintain impetus for the programme. The first year undoubtedly provided a significant burden of work for the A\&E staff during a retrieval, in addition to the normal work load of the department. Once working well, it has now fitted in to the work patterns of the department. A busy unit is unfortunately the location of a high proportion of irredeemable deaths in a relatively young age group. This system allows for benefits not only for relatives who see some good coming from a tragic situation, for the patients who will receive the transplanted kidneys, but also for staff morale in the $A \& E$ department.

In summary, the NHBD programme in Leicester has proved to be very successful, requiring reorganisation of resources and personnel from the transplant service and $A \& E$ department. In addition, the utilisation of existing facilities and personnel within the department has greatly helped to complement the programme. Much more important has been the positive psychological support provided for grieving relatives and boost in morale for $A \& E$ staff which comes with a successful retrieval. The programme has provided a significant increase to the renal transplant rate in Leicestershire and we would strongly urge other hospitals with large $A \& E$ departments to pursue setting up similar programmes.

Our thanks to all medical and nursing staff at the Leicester Royal Infirmary and Leicester General Hospital who are involved in or have supported the NHBD programme in the past three years.

1 United Kingdom Transplant Support Service Authority Report. Bristol: UKTSSA, 1991,1992,1993.

2 Varty K, Veitch PS, Morgan JDT, Kehinde GO, Donnelly PK, Bell PRF. Response to organ shortage: kidney retrieval PK, Bell PRF. Response to organ shortage: kidney retrieval programm.

3 Ruers TJM, Vroeman JPAM, Koostra G. Non-heart beating donors: a successful contribution to organ procurement Transplant Proc 1985;18:408-10.

4 Costelao AM, Grino JM, Gonzalez C. Long term renal function of kidneys transplanted from non-heart beating cadaver donors. Transplant Proc 1991;23:2584-6.

5 Kellerman AL, Hackman BB, Somes G. Predicting the outcome of unsuccessful prehospital advanced cardiac life support. $\mathcal{F} A M A$ 1993;270:1433-6.

6 Gray WA, Capone RJ, Most AS. Unsuccessful emergency medical resuscitation-are continued efforts in the Emergency department justified. $N$ Engl $\mathcal{F}$ Med 1991;325:13938.

7 Booster MH, Wignen RMH, Ming Y, Vroemen JPAM, Koostra G. In situ perfusion of kidneys from non-heart Koostra G. In situ perfusion of kidneys from non-heart beating donors:

8 Advanced Life Support Working Party of the European Resuscitation Council, 1992. Guidelines for advanced life support. Resuscitation, 1992;24:111-21.

9 Hassan TB, Hickey FG, Goodacre S, Bodiwala GG. Pre-hospital cardiac arrest in Leicestershire-targetting areas for improvement. $\mathcal{F}$ Accid Emerg Med (in press).

10 Hamer DW, Gordon MWG, Cusack S, Robertson CE. Survival from cardiac arrest in an $A \& E$ department: the impact of out of hospital advisory defibrillation. Resuscitation 1993;26:31-6.

11 Gore SM. Ross RM, Wallwork J. Availability of transplantable organs from brain stem dead donors in intensive care units. $B M F$ 1991;302:149-53.

12 Conference of Medical Royal Colleges and their Faculties in the UK. Report of the Working Party on the supply of donor the UK. Report of the Working Party on the supply of
organs for transplantation. London: HMSO, 1987.

13 Stein A, Hope T, Baum JD, Organ transplantation: approaching the donor's family. BMF 1995;310:1149-50. 